\title{
Catalytic Dehydrogenation of para-Diethyl Benzene to para-Divinyl Benzene over Iron Oxide Supported Catalyst
}

\author{
Vivek K. Srivastava, Nagesh Sharma, Raksh V. Jasra* \\ Reliance Research and Development Center, Vadodara Manufacturing Division, \\ Reliance Industries Ltd., Vadodara-391346, Gujarat, India
}

Received: 18th July 2018; Revised: 28th November 2018; Accepted: 17th December 2018; Available online: 30th April 2019; Published regularly: 1st August 2019

\begin{abstract}
The vapor-phase catalytic dehydrogenation of para-diethyl benzene (PDEB) to para-divinyl benzene (PDVB) with super-heated steam as a diluent was investigated using alumina supported iron oxide catalyst system. During the catalytic dehydrogenation reaction, ethyl styrene (EST) and thermal cracking products were observed as side products. It was found that various reaction parameters influence the rate of dehydrogenation reaction. However, the reaction is favored by high temperature and low reaction pressure. Moreover, addition of potassium into iron-oxide catalyst acts as a promoter and thereby increases the efficiency of the catalyst. The conversion of PDEB and yield of PDVB also increases as the Water/PDEB flow ratio increases. Copyright (C) 2019 BCREC Group. All rights reserved
\end{abstract}

Keywords: Dehydrogenation; para-Diethyl Benzene; para-Divinyl Benzene; Supported Iron Catalyst

How to Cite: Srivastava, V.K., Sharma, N., Jasra, R.V. (2019). Catalytic Dehydrogenation of paraDiethyl Benzene to para-Divinyl Benzene over Iron Oxide Supported Catalyst. Bulletin of Chemical Reaction Engineering \& Catalysis, 14 (2): 301-308 (doi:10.9767/bcrec.14.2.2963.301-308)

Permalink/DOI: https://doi.org/10.9767/bcrec.14.2.2963.301-308

\section{Introduction}

The para-divinylbenzene (PDVB) is an extremely versatile cross-linking agent. It has been used to manufacture adhesives, plastics, elastomers, ceramics, biological materials, coatings, catalysts, membranes, pharmaceuticals, specialty polymers and ion exchange resins. It is used to cross-link polystyrene to increase solvent resistance, heat distortion, impact strength, tensile strength, hardness and retained good optical and electrical properties. A small amount of divinylbenzene in styrene polymerization makes the polymer insoluble in most of the solvents. Therefore, para-

\footnotetext{
* Corresponding Author.

E-mail: rakshvir.jasra@ril.com (R.V. Jasra)

Telp: +91-265-2616313
}

Divinylbenzene (PDVB) is used in industrial scale for the production of polystyrene ion exchange resin beads [1-4]. PDVB is produced by the catalytic dehydrogenation of para-diethyl benzene (PDEB) at higher temperature in the presence of superheated steam over iron-based supported catalyst system (Scheme 1) similar to the catalytic dehydrogenation of Ethylbenzene (EB) to styrene (ST) [5-9].

Although the PDEB catalytic dehydrogenation is similar to the EB dehydrogenation in many ways, however, the former reaction is relatively more complex [10], because of the following reasons (Scheme 2): (a). it involves two consecutive dehydrogenation steps; PDEB to EST and finally EST to PDVB, hence, the employed catalyst system should be effective enough to successfully carry-out the second dehydrogena- 
tion step [10]; (b). higher reaction temperature $\left(>550{ }^{\circ} \mathrm{C}\right)$, which is just below temperature when thermal cracking organic compounds becomes significant [11-12]; (c) a large amount of superheated steam at reaction pressure used to shift the equilibrium in forward direction and preserve the catalyst activity by avoiding formation of carbonaceous deposits at such a high temperature [13-14].

The catalytic dehydrogenation product stream, usually contains PDVB and ethyl styrene (EST) as major products and benzene, toluene, vinyl toluene, ethyltoluene, xylene, styrene, ethylbenzene, and naphthalene as minor components [15-16]. The distillation of the dehydrogenation product mixture affords a mixture of PDVB and EST. During dehydrogenation reaction, the meta- and para-isomer of PDVB are also obtained, the ortho-isomer rearranges to naphthalene. However, the higher quantity of naphthalene adversely affect the properties of copolymer and also impart an intolerable odor. Therefore, naphthalene concentration needs to be minimized in the finishing distillation. Moreover, the purification of PDVB is also complicated due to its tendency to polymerize at low temperatures to form crosslinked gelatinous polymers insoluble in organic solvents. Purification of PDVB has been reported by cuprous chloride complex mixture solution of PDVB treated with $\mathrm{Cu}_{2} \mathrm{Cl}_{2}$ followed by thermal decomposition of the complex yielded 100\% PDVB [17].

The supported iron-based catalyst system was found to be most effective catalyst for dehydrogenation of ethyl benzene to styrene [18-
22]. However, potential of such catalyst system is not explored in detail dehydrogenation of PDEB to PDVB. Therefore, the objective of present research work was to explore the potential of supported iron-based catalyst and effect of promoter incorporation in such supported catalyst system towards dehydrogenation of PDEB to PDVB. In the present short communication, we report the synthesis of iron oxide-, alkali metal (potassium)-promoted alumina supported catalyst system and their catalytic activity towards dehydrogenation of PDEB to PDVB. The effect of reaction parameters namely reaction temperature, $\mathrm{PDEB} /$ steam ratio alkali promoter on product selectivity is investigated in detail. It was demonstrated clearly that for the selective conversion of PDEB to PDVB, which involves two-steps of dehydrogenation, incorporation of potassium promoter into the ironoxide based catalyst was critical. It was proposed that the presence of potassium oxide into iron-oxide based catalyst system positively enhanced the required amount of selective oxygen which are responsible to carry-out the second dehydrogenation step of EST to PDVB.

\section{Materials and Methods}

The crystallinity of catalysts was determined by "X-ray Powder Diffractometer" (D8 ADVANCE-Bruker AXS). The diffractograms are recorded using $\mathrm{Cu}-\mathrm{Ka}(1.54 \AA)(40 \mathrm{kV} / 30$ $\mathrm{mA})$ radiation in the $2 \theta$ range between $3^{0}$ and $90^{\circ}$, with a $2 \theta$ step of $0.02^{\circ}$ for 0.75 sec. per point.

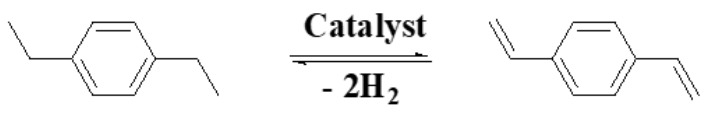

p-Diethyl benzene (PDEB)

p-Divinyl benzene (PDVB)

Scheme 1. The catalytic dehydrogenation of PDEB to PDVB

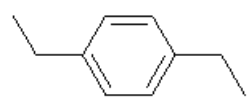

$$
\frac{\text { Catalyst }}{=-\mathrm{H}_{2}}
$$

$p$-Diethyl benzene (PDEB)



Ethyl styrene (EST)

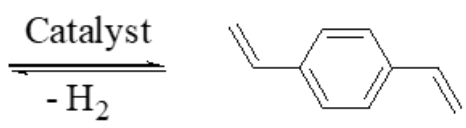

p-Divinyl benzene (PDVB)

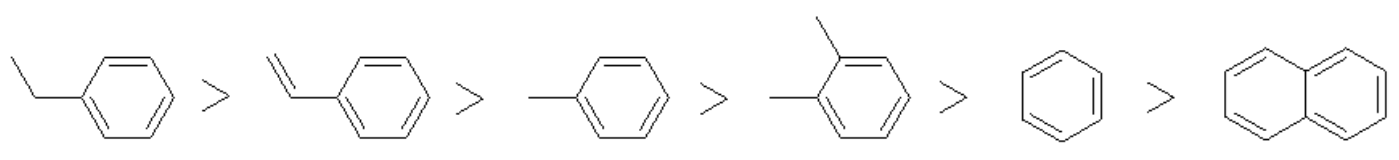

By-products

Scheme 2. Reaction pathways and by-products of catalytic dehydrogenation reaction of PDEB to PDVB 


\subsection{Materials and Catalyst Testing}

The precursor chemicals used for synthesis of catalyst and their evaluation studies are given in Table 1 . The catalytic reaction was performed in a stainless steel tube reactor (SSTBR) with $\sim 11.0 \mathrm{~mm}$ ID and a known quantity of catalyst was used. The flow diagram of catalyst testing unit (CTU) is shown in Figure 1 . The catalyst test unit was fabricated using a furnace (FTS Applied Test Systems Inc.) to supply the heat to the reactor (maximum temperature of $1100 \quad{ }^{\circ} \mathrm{C}$ ), two feed pumps (KNAUER) to supply the flow of PDEB and water, a reactor, pre-heater, condenser, and liquid-gas separator, and all (were made by stainless steel) as well as a chiller unit (M/S JULABO LABORATECHNIK GMBH, D-77960 Seelbach/Germany).

\subsection{Synthesis and Characterization of Iron-} oxide Supported on Alumina Catalysts

Typically, $4 \% \mathrm{Fe}_{2} \mathrm{O}_{3}$ per gram on $\mathrm{Al}_{2} \mathrm{O}_{3}$ were synthesized. The alumina-supported iron oxide catalyst used in this work was prepared by impregnation method. Commercial $\gamma-\mathrm{Al}_{2} \mathrm{O}_{3}$ (BET surface area: $163 \mathrm{~m}^{2} / \mathrm{g}$; bulk density: 0.35 g/cm ${ }^{3}$; Cl: $\leq 0.15$ wt.\%; and Fe: $\leq 0.03$ wt.\%) was calcined at $600{ }^{\circ} \mathrm{C}$ for $3 \mathrm{~h}$ before use. The active component iron ( $\mathrm{Fe}$ ) was introduced by impregnation of the support with aqueous solution of iron nitrate; $\mathrm{Fe}\left(\mathrm{NO}_{3}\right)_{3} \cdot 9 \mathrm{H}_{2} \mathrm{O}$. Alkali metal, potassium $(\mathrm{K})$ promoted catalyst, were prepared by co-impregnation using aqueous solution of both potassium carbonate $\left(\mathrm{K}_{2} \mathrm{CO}_{3}\right)$ and $\mathrm{Fe}\left(\mathrm{NO}_{3}\right)_{3} \cdot 9 \mathrm{H}_{2} \mathrm{O}$. The slurry impregnation was conducted for $24 \mathrm{~h}$ and then the catalysts were dried at $120^{\circ} \mathrm{C}$ in air for $4 \mathrm{~h}$, and finally calcined at $600{ }^{\circ} \mathrm{C}$ in air for $4 \mathrm{~h}$.

\subsection{Catalyst Evaluation Studies of PDEB De-} hydrogenation Reaction and Product Analysis

As a pretreatment step, the catalyst was first activated under a nitrogen flow by raising the furnace temperature to the desired reaction temperature. The catalyst was maintained at reaction temperature for 30 minute before introducing super-heated steam, which was generated in pre-heater by supplying water. Then PDEB was passed through sparger by sparging nitrogen gas. PDEB and steam were mixed and

Table 1. The supplier and purity of chemicals used

\begin{tabular}{cllc}
\hline Sr. No. & \multicolumn{1}{c}{ Chemicals } & \multicolumn{1}{c}{ Suppliers } & Purity (\%) \\
\hline 1 & Iron(III) nitrate nonahydrate & Sigma-Aldrich Pvt. Ltd. & 99.0 \\
2 & Potassium Carbonate & Sigma-Aldrich Pvt. Ltd. & 99.0 \\
3 & Commercial Gamma-Alumina & Sigma-Aldrich Pvt. Ltd. & 99.0 \\
4 & Sodium Hydroxide & Sigma-Aldrich Pvt. Ltd. & 99.0 \\
5 & Para-Diethyl Benzene & Reliance Industries Ltd. & 99.0 \\
\hline
\end{tabular}

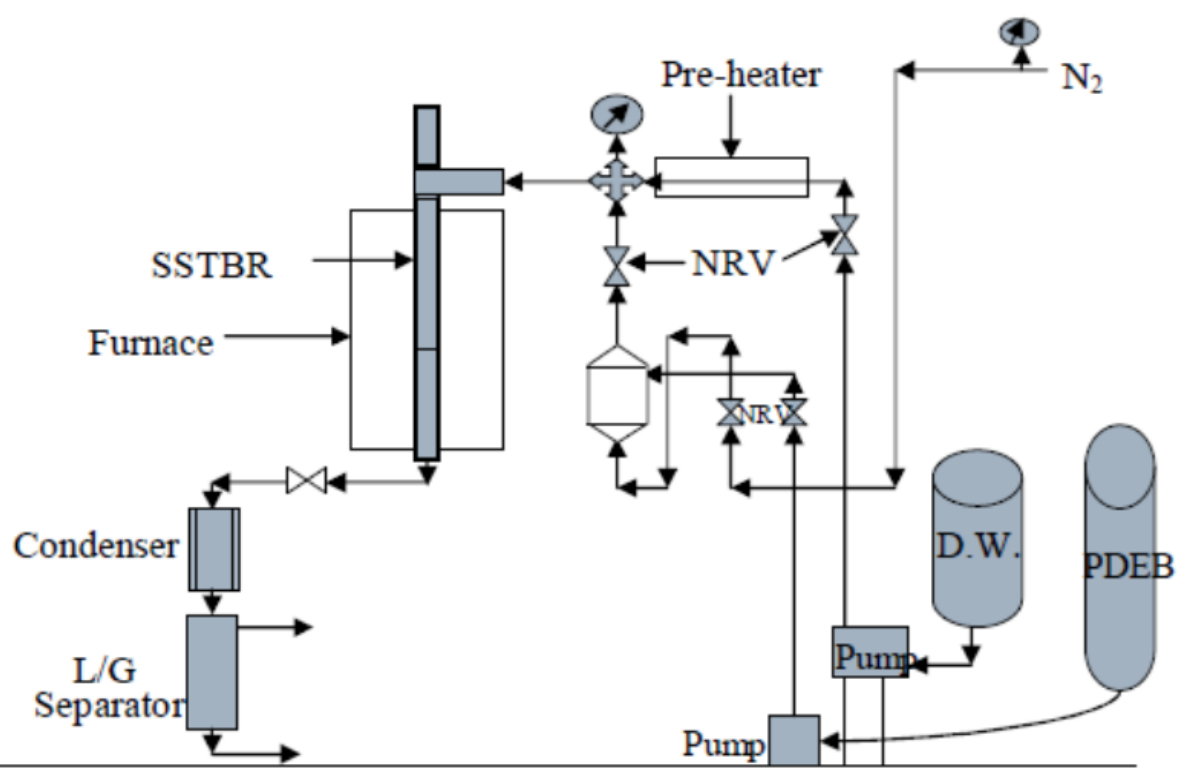

Figure 1. Flow-diagram of catalyst testing unit 
fed to the reactor. Then the mixed feed is passed over iron oxide-based catalyst along with superheated steam at 600-700 ${ }^{\circ} \mathrm{C}$ at atmospheric pressure. The product stream first goes to condenser and then to a gas-liquid separator, where liquid product mixtures are collected at the bottom and gases at the top.

A two-phase liquid product (water and organic) was obtained. The organic phase contains a mixture of PDEB, EST, benzene, toluene, EB, ST, and Xylene, as well as unreacted PDEB (Scheme 2). Due to the proximity of boiling points of these components, the separation was difficult. Water was removed by extraction and the organic phase was passed through alumina pad and separated out. Finally the organic mixture was subjected to GC analysis. The liquid products were analyzed with a FID gas chromatograph of VARIAN Company using capillary column Resteck-5 of 30 meter length and $0.25 \mathrm{~mm}$ diameter. The condition of $\mathrm{GC}$ FID were injector port temperature: $200{ }^{\circ} \mathrm{C}$; carrier gas (He) make-up flow: $30 \mathrm{~mL} / \mathrm{min}$; column oven temperature: $250{ }^{\circ} \mathrm{C} ; \mathrm{H}_{2}$ flow: 30 $\mathrm{mL} / \mathrm{min}$; air flow: $300 \mathrm{~mL} / \mathrm{min}$, and detector temperature: $250{ }^{\circ} \mathrm{C}$. The conversion (\%) of PDEB $\left(X_{P D E B}\right)$, selectivity (\%) $\left(S_{P D V B}\right)$, and yield (\%) $\left(Y_{P D V B}\right)$ of PDVB were calculated using Equations (1-3), in which $n_{P D E B, \text { in }}$ is mole of PDEB charged to reactor, $n_{P D E B, \text { out }}$ is mole of PDEB remained in outlet, $n_{P D V B, \text { out }}$ is mole of PDVB produced in outlet, and $n_{\text {products,out }}$ is total moles of all products produced in outlet.

$$
\begin{aligned}
& X_{P D E B}(\%)=\frac{n_{P D E B, \text { in }}-n_{P D E B, \text { out }}}{n_{P D E B, \text { in }}} x 100 \% \\
& S_{P D V B}(\%)=\frac{n_{P D V B, \text { out }}}{n_{\text {products,out }}} x 100 \% \\
& Y_{P D V B}(\%)=\frac{X_{P D E B} . S_{P D V B}}{100}
\end{aligned}
$$

\section{Results and Discussion}

The synthesized catalysts were characterized by different physiochemical characterization techniques. The BET surface area and pore volume of catalyst was measured at 200 ${ }^{\circ} \mathrm{C}$ after degassing for $7 \mathrm{~h}$. The results are shown in Table 2. The surface area and pore volume of the catalyst is observed to decrease on loading iron oxide on alumina surface. The XRD pattern of pure alumina and impregnated catalyst are presented in Figure 2. The comparison of XRD patterns of alumina with that of catalyst shows that the XRD patterns of both alumina and catalyst are similar. However, the peak intensities of the supported catalyst have been reduced compared to the alumina because the support surface was covered by the layers of impregnated iron-oxides. Moreover, in the XRD patterns of supported catalyst no peak representing iron oxide was observed. The possible reason may be because the ironoxide is highly dispersed over the support surface which are out of the detection limit of

Table 2. The surface area and pore volume of catalysts

\begin{tabular}{rcc}
\hline Sample & Surface Area $\left(\mathrm{m}^{2 / \mathrm{g})}\right.$ & Pore Volume $\left(\mathrm{cm}^{3 / \mathrm{g})}\right.$ \\
\hline Alumina powder & 163 & 0.49 \\
$4 \% \mathrm{Fe}_{2} \mathrm{O}_{3} / \mathrm{Al}_{2} \mathrm{O}_{3}$ & 142 & 0.39 \\
\hline
\end{tabular}

*Single point adsorption total pore volumes of pores
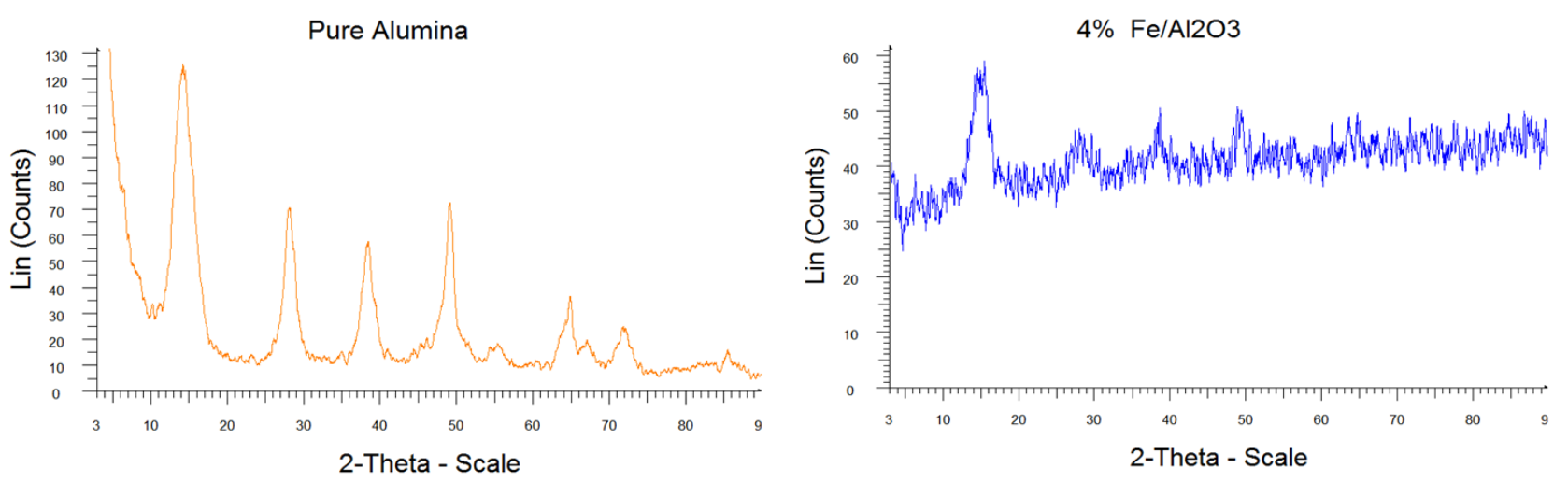

Figure 2. The p-XRD patters of the pure Alumina and $4 \% \mathrm{Fe}_{2} \mathrm{O}_{3} / \mathrm{Al}_{2} \mathrm{O}_{3}$ catalysts 
XRD. The effect of various parameters on dehydrogenation reaction have been studies and described below.

\subsection{Effect of Reaction Temperature}

The dehydrogenation of PDEB to PDVB is endothermic and volume-increasing reaction, therefore, high temperature and low pressure favor for the high conversion of PDEB. As a result, reactions were carried out from $500{ }^{\circ} \mathrm{C}$ to $550^{\circ} \mathrm{C}$, the flow rate of water and PDEB were 90 and $20 \mathrm{~mL} / \mathrm{h}$ respectively using ironsupported alumina catalysts. However, no significant PDEB conversion was observed under the employed reaction temperature. The reaction temperature was further increased above $550{ }^{\circ} \mathrm{C}$. The observed results indicated that $\mathrm{PDEB}$ conversion increases with rise in the reaction temperature and maximum PDEB conversion $37 \%$ observed at $700{ }^{\circ} \mathrm{C}$.

On the other hand, three major products EST, PDVB and lower hydrocarbons were observed during the reaction temperature varia-

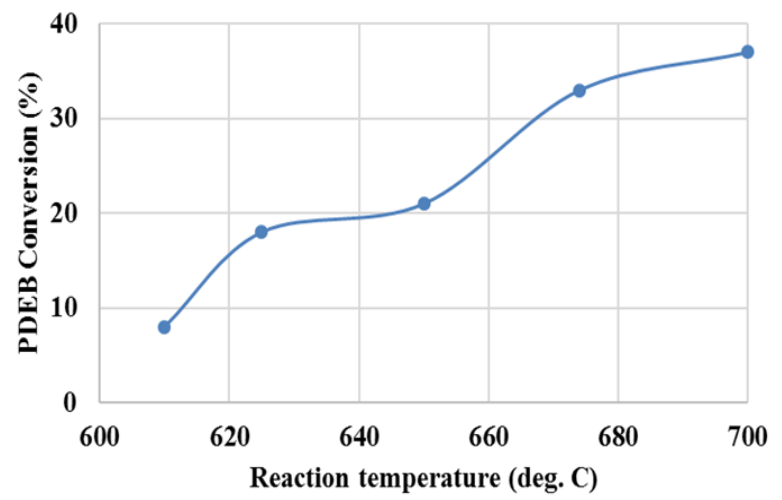

tion. As mentioned earlier in (Scheme 2), catalytic dehydrogenation of PDEB to PDVB is a two-step reaction wherein PDEB is converted into EST followed by further dehydrogenation of EST to PDVB. Meanwhile, formation of lower hydrocarbon occurs by thermal degradation of these aromatic hydrocarbons at higher reaction temperature. Therefore, employed catalyst performance and reaction conditions become critical in determining the desired product selectivity. Under the employed reaction conditions, on varying the reaction temperature from 610 to $700{ }^{\circ} \mathrm{C}$, the EST yield increased from 8 to $22 \%$, thermal cracking products yield increased from 1 to $10 \%$ and maximum $5 \%$ PDVB yield was observed at $700{ }^{\circ} \mathrm{C}$ (Figure 3). The above results indicates that while using $\mathrm{Fe}_{2} \mathrm{O}_{3} / \mathrm{Al}_{2} \mathrm{O}_{3}$ catalyst system, although the higher reaction temperature improves the first dehydrogenation step PDEB conversion to EST but the activity of employed catalyst was not adequate towards the second dehydrogenation step of EST to PDVB which may require more quantity of labile surface oxygen to carry-out

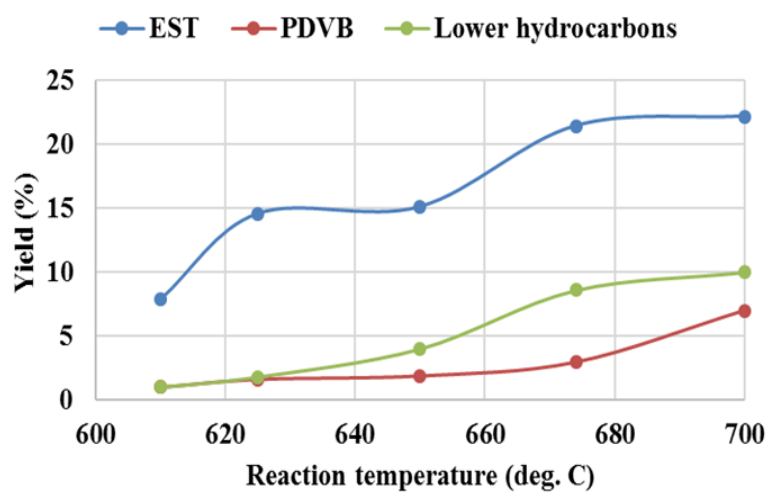

Figure 3. Effect of reaction temperature: $\mathrm{Fe}_{2} \mathrm{O}_{3} / \mathrm{Al}_{2} \mathrm{O}_{3}$ catalyst volume $=5.5 \mathrm{~mL}$, reaction pressure $=1$ atm, PDEB flow rate $=20 \mathrm{~mL} / \mathrm{h}$, Water flow rate $=90 \mathrm{~mL} / \mathrm{h}$
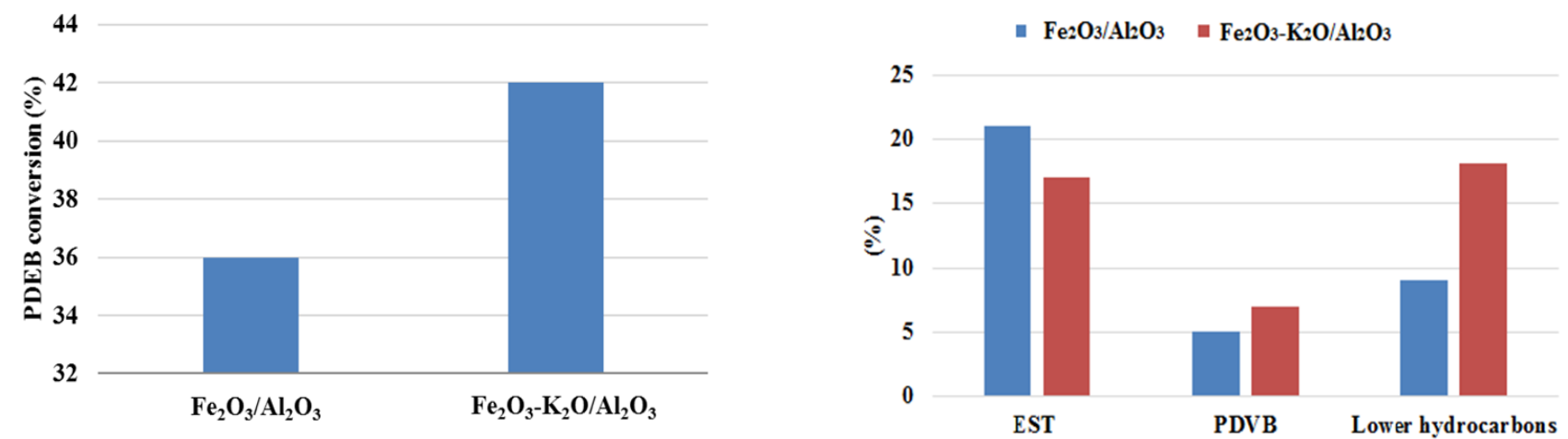

Figure 4. Effect of promoter: Catalyst volume $=5.5 \mathrm{~mL}, \mathrm{PDEB} /$ water flow $=20 / 90 \mathrm{~mL} / \mathrm{hr}$; Reaction temperature $=700^{\circ} \mathrm{C}$; reaction pressure $=1 \mathrm{~atm}$ 
subsequent dehydrogenation step. Therefore, it became inevitable to increase the concentration labile surface oxygen by using a suitable promoter into $\mathrm{Fe}_{2} \mathrm{O}_{3} / \mathrm{Al}_{2} \mathrm{O}_{3}$ catalyst system.

\subsection{Effect of Incorporation of Potassium Pro- moter in $\mathrm{Fe}_{2} \mathrm{O}_{3} / \mathrm{Al}_{2} \mathrm{O}_{3}$ Catalyst System}

To further improve that performance of $\mathrm{Fe}_{2} \mathrm{O}_{3} / \mathrm{Al}_{2} \mathrm{O}_{3}$ catalyst system particularly towards second dehydrogenation step which EST to PDVB, the catalyst system was modified by using alkali promoters which will increase the quantity of labile surface oxygen. As shown in Figure 4, the PDEB conversion increases from 36 to $42 \%$ with promoted $\mathrm{Fe}_{2} \mathrm{O}_{3}-\mathrm{K}_{2} \mathrm{O} / \mathrm{Al}_{2} \mathrm{O}_{3}$ catalysts. The yield of PDVB increases from 5 to 7 $\%$, while EST yield decreases from 21 to $17 \%$, but yield of lower products was increased from 9 to $18 \%$. This shows that the promoter increases the performance of catalyst in terms of the PDEB conversion.

The structure of alkyl aromatics play a vital role to decide the product yields. The yield of the final products mainly depends upon the interaction of selective oxygen to alkyl proton molecules. As shown in Scheme 3, unlike the $\mathrm{EB}$, the $\mathrm{PDEB}$ dehydrogenation reaction requires additional selective oxygen on the catalyst surface to complete the two-step dehydrogenation reaction towards desired PDVB. Therefore, in order to achieve high selectivity towards PDVB, the catalyst system requires more number of selective oxygen on their surface. In the case of potassium alkali promoted $\mathrm{Fe}_{2} \mathrm{O}_{3}-\mathrm{K}_{2} \mathrm{O} / \mathrm{Al}_{2} \mathrm{O}_{3}$ catalyst provide additional surface oxygen in comparison to $\mathrm{Fe}_{2} \mathrm{O}_{3} / \mathrm{Al}_{2} \mathrm{O}_{3}$ based catalyst, which resulted enhanced PDVB selectivity while using former catalyst system. The observed results in the present article also support the assumption as the PDEB conversion increased from 36 to $42 \%$ along with PDVB yield while using $\mathrm{Fe}_{2} \mathrm{O}_{3}-\mathrm{K}_{2} \mathrm{O} / \mathrm{Al}_{2} \mathrm{O}_{3}$ as catalysts which possesses additional selective surface oxygen in comparison to $\mathrm{Fe}_{2} \mathrm{O}_{3} / \mathrm{Al}_{2} \mathrm{O}_{3}$ based catalyst system.

\subsection{Effect of Variation of Water Flow Rate}

The effect of water/PDEB flow ratio on the reaction was also investigated. During the experiment PDEB flow rate $(20 \mathrm{~mL} / \mathrm{h})$, was kept



Ethyl benzene dehydrogenation

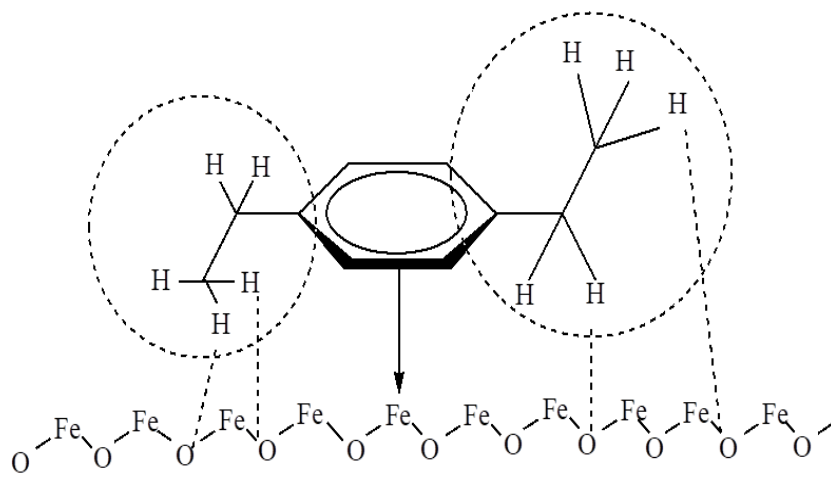

Diethyl benzene dehydrogenation

Scheme 3. In-sight of EB and PDEB dehydrogenation reactions

PDEB conversion (\%)

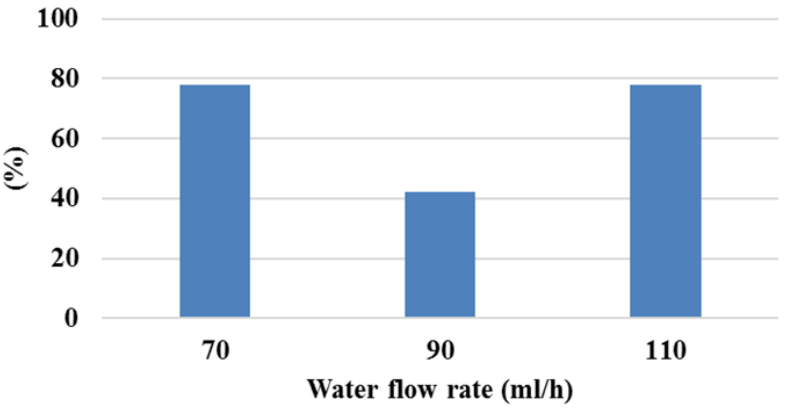

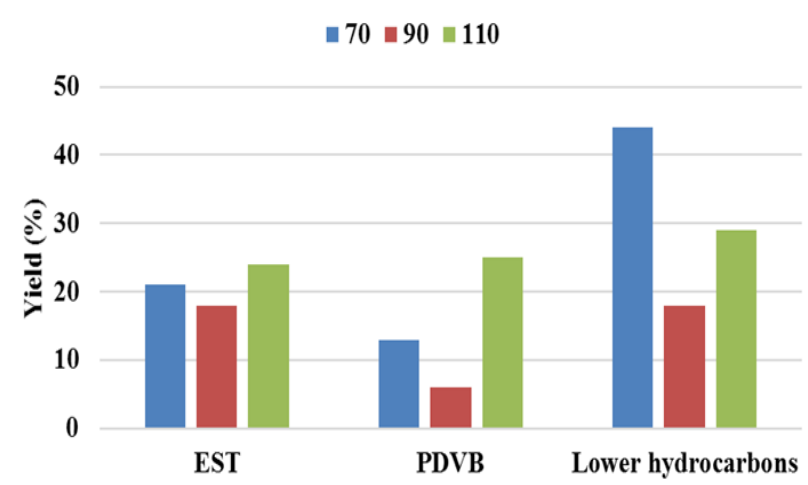

Figure 5. Effect of flow rate: $\mathrm{Fe}_{2} \mathrm{O}_{3}-\mathrm{K}_{2} \mathrm{O} / \mathrm{Al}_{2} \mathrm{O}_{3}$ catalyst volume $=5.5 \mathrm{~mL}$, PDEB flow $=20 \mathrm{~mL} / \mathrm{h}$, reaction temperature $=700{ }^{\circ} \mathrm{C}$, reaction pressure $=1 \mathrm{~atm}$ 
constant and the water flow rate was varied in order to vary the $\mathrm{PDEB} /$ water ratio. As shown in Figure 5, at $70 \mathrm{~mL} / \mathrm{h}$ water flow rate, $\sim 78 \%$ of PDEB conversion was obtained, the yield of EST and PDVB were obtained $22 \%$ and $12 \%$ respectively, but yield of lower product obtained was as high as $42 \%$. At the $90 \mathrm{~mL} / \mathrm{h}$ water flow rate, $\sim 42 \%$ of PDEB conversion was obtained, the yield of EST and PDVB obtained were $17 \%$ and $6 \%$ respectively, but yield of lower product obtained was $17 \%$. While at 110 $\mathrm{mL} / \mathrm{h}$ water flow rate, again $\sim 78 \%$ of $\mathrm{PDEB}$ conversion was obtained and the yield of EST and PDVB obtained were $24 \%$ and $25 \%$ respectively and the yield of lower product obtained was $30 \%$. Such higher PDVB yield (25 $\%)$ observed at higher water/PDEB flow ratio, indicated that besides the catalyst performance, the employed process conditions is also a critical parameter required to shift the equilibrium in forward direction and large volume of steam helps to preserve the catalyst activity by avoiding formation of carbonaceous deposits due to thermal degradation at higher reaction temperature.

\section{Conclusion}

The efficiency of alumina supported ironoxide based catalysts and alkali metal (potassium) promoted iron-oxide catalyst was investigated towards dehydrogenation of PDEB to PDVB. It was found that the PDEB conversion and yields of PDVB and EST increased significantly by incorporation of potassium oxide promoter into the iron-oxide catalyst $\left(\mathrm{Fe}_{2} \mathrm{O}_{3}\right.$ $\mathrm{K}_{2} \mathrm{O} / \mathrm{Al}_{2} \mathrm{O}_{3}$ ). Therefore, it can be concluded that the presence of potassium oxide enhanced catalyst performance by increasing required liable surface oxygen which improved the performance of catalyst system especially for second dehydrogenation step of EST to PDVB in comparison to the catalyst system without any potassium oxide.

\section{Acknowledgements}

The authors are thankful to Reliance Industries Ltd. for the consent of publishing the work and funding to carry-out the research work.

\section{References}

[1] Goseki, R., Tanaka, S., Ishizone, T., Hirao, A. (2018). Living Anionic Polymerization of 1,4Divinylbenzene and Its Derivatives. React. and Function. Polym. 127: 94-112.
[2] Lopez-Dominguez, P., Hernández-Ortiz, J.C., Vivaldo-Lima, E. (2018). Modeling of RAFT Copolymerization with Crosslinking of Styrene/Divinylbenzene in Supercritical Carbon Dioxide. Macromol. Theory Simul. 27: 1700064-1700078.

[3] Rabelo, D., Coutinho, F.M.B. (1994). Structure and Properties of StyreneDivinylbenzene Copolymers. Polym. Bulletin, 33: 493-496.

[4] Okaya, O., Kayab, D., Pekcan, O. (1999). Free-radical Crosslinking Copolymerization of Styrene and Divinylbenzene: Real Time Monitoring of the Gel Effect Using Fluorescence Probe. Polymer. 40: 6179-6187.

[5] Rao, K.N., Reddy, B.M., Park, S-E. (2010) Novel $\mathrm{CeO}_{2}$ Promoted $\mathrm{TiO}_{2}-\mathrm{ZrO}_{2}$ Nano-oxide Catalysts for Oxidative Dehydrogenation of $p$ Diethylbenzene Utilizing $\mathrm{CO}_{2}$ as Soft Oxidant. Appl. Catal. B: Environ. 100: 472-480.

[6] Chen, S., Sun, A., Qin, Z., Wang, J. (2003). Reaction Coupling of Diethylbenzene Dehydrogenation with Water-Gas Shift over Alumina-Supported Iron Oxide Catalysts. Catal. Commun. 4: 441-447.

[7] Koehle, M., SaraAi, E., Dauenhauer, P., Lobo, R.F. (2017). Production of p-Methylstyrene and p-Divinylbenzene from Furanic Compounds. ChemSusChem. 10: 91- 98.

[8] Tomiho, A., Toyoki, F., Yasuhiko, I., Masahiro, M. (1995). Process for Preparing Divinyl Benzene. US Patent 5401895.

[9] Miura, H., Ansai, R., Mizushima, Y., Kurita, A. (1993). Synthesis of Divinylbenzene Synthesis by the Dehydrogenation of Diethylbenzene over Iron-Based Mixed Oxide Catalysts. Intern. J. Chem. Engineer. 33: 124-128.

[10] Forni, L., Valerio, A. (1971) Kinetics of Diethylbenzene Catalytic Dehydrogenation Ind. Eng. Chem. Process Des. Dev. 10: 552-558.

[11] Zeynali, M. E. (2011). Investigation of the Effect of Diffusion Process in the Catalyst Pellet on Overall Reaction Rate of Dehydrogenation of Diethylbenzne to Divinylbenzne Def. and Diffus. Forum Solid State Data, Pt. A: Defect and Diffusion Forum 312-315: 7-12.

[12] Zeynali, M.E. (2011). Effects of Different Processing Parameters on Divinylbenzene (DVB) Production Rate. Chem. Sci. J. 2: CSJ-22.

[13] Zeynali, M.E., Soltani, I. (2010). Effects of Processing Factors on Microstructure and Diffusivity of Diethylbenzene Dehydrogenation Catalyst. Def. and Diffus. Forum Solid State Data, Pt. A: Defect and Diffusion Forum. 297-301: 233-238. 
[14] Zeynali, M.E. (2009). A Realistic Method to Describe the Role of Diffusion in Catalyst Design. Def. and Diffus. Forum Solid State Data, Pt. A: Defect and Diffusion Forum. 294: 65-76.

[15] Chen, S., Li, X-X., Shu, L., Somsundaran, P., Li, J-R. (2017). The High Efficient Separation of Divinylbenzene and Ethylvinylbenzene Isomers Using High Performance Liquid Chromatography with Fe-based MILs Packed Columns. J. of Chromat. A. 1510: 25-32.

[16] Saccoccia, B., Bohnsack, A.M., Waggoner, N.W., Cho, K.H., Lee, J.S., Hong, D-Y., Lynch, V.M., Chang, J-S., Humphrey, S.M. (2015). Separation of p-Divinylbenzene by Selective Room-Temperature Adsorption inside Mg-CUK-1 Prepared by Aqueous Microwave Synthesis. Angew. Chem. 127: 5484-5488.

[17] Meek, P.D., David, R. (1965). Separation of Divinylbenzene from a Mixture Comprising Divinylbenzene and Ethylvinylbenzene. US Patent 3217052.

[18] Butler, J.R., Merrill, J.T., Jacobsen, A.M., (2009). Dehydrogenation Process. US Patent 7507385 .
[19] Melian-Cabrera, I., Zarubina, V,, Nederlof, C., Kapteijnd, F., Makkeed, M. (2018). An Insitu Reactivation Study Reveals the Supreme Stability of g-Alumina for the Oxidative Dehydrogenation of Ethylbenzene to Styrene. Catal. Sci. Technol., 8: 3733-3736.

[20] Kotelnikov, G.R., Bespalov, V.P., Sidnev, V.B., Kachalov, D.V. (2009). Production and Operation of Dehydrogenation Catalysts. Catal. Ind. 1: 66-69.

[21] Hong, D.-Y., Vislovskiy, V.P., Park, S.-E., Park, M.-S., Yoo, J.S., Chang, J.-S. (2005) Dehydrogenation of Ethylbenzene with Carbon Dioxide as Soft Oxidant over Supported Vanadium-Antimony Oxide Catalyst. Bull. Korean Chem. Soc. 26: 1743-1748.

[22] Yoo, J.S. (1996). Gas Phase Oxygen Oxidation of alkylaromatics over CVD $\mathrm{Fe} / \mathrm{Mo} /$ borosilicate Molecular Sieve, $\mathrm{Fe} / \mathrm{Mo} / \mathrm{DBH}$ VII. Oxidative Dehydrogenation of Alkylaromatics. Appl. Catal. 142: 19-29. 